\title{
Catalysis by hydroxyapatite alone and modified by sodium nitrate: a simple and efficient procedure for the construction of carbon- nitrogen bonds in heterogeneous catalysis
}

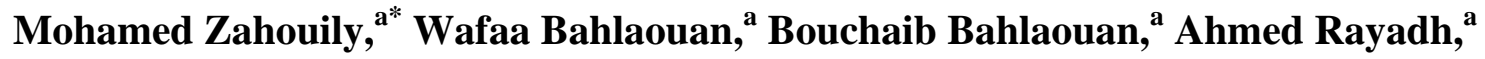 \\ and Saïd Sebti ${ }^{\mathbf{b}}$ \\ ${ }^{a}$ Laboratoire de Catalyse, Chimiométrie et Environnement, UFR de Chimie Appliquée, \\ Université Hassan II, Faculté des Sciences et Techniques, Mohammadia B. P. 146, 20650 Maroc \\ ${ }^{b}$ Laboratoire de Chimie Organique Appliquée et Catalyse, Université Hassan II, Faculté des \\ Sciences, Ben M'Sik B. P. 7955, Casablanca, Maroc \\ E-mail:mzahouily@yahoo.fr
}

(received 11 Feb 05; accepted 27 Apr 05; published on the web 01 May 05)

\begin{abstract}
Application of hydroxyapatite modified by sodium nitrate as heterogeneous catalysts for the Michael type addition reaction of aliphatic and aromatic amines to $\alpha, \beta$-unsaturated carbonyl compounds is presented. Modifying hydroxyapatite by sodium nitrate significantly enhances the rate and yield of the reaction. This catalyst is used as the catalyst for a facile synthesis of $\beta$ amino acid under heterogeneous conditions.
\end{abstract}

Keywords: Hydroxyapatite, sodium nitrate, carbon-nitrogen bond, $\beta$-amino acid, heterogeneous catalysis, recyclable catalyst

\section{Introduction}

$\beta$-Amino-acid are in important class of compounds in modern pharmaceutical chemistry. ${ }^{1}$ The Michael type condensation of an aliphatic amine and an $\alpha, \beta$-unsaturated carbonyl compound is a convenient route for the synthesis of $\beta$-amino acid compounds. ${ }^{2}$ This condensation is normally carried out in the presence of a Lewis acid, ${ }^{3}$ although, in same cases the reaction occurs with no special activation, ${ }^{4}$ in others stronger reaction conditions are required. ${ }^{5}$ Of late there has been interest in carrying out synthetic organic reactions under conditions which do not require separation of the product from other organic materials (such as the base), which are fast, effective, and which do not require heating or the use of large quantities of solvent.

In an attempt to meet these conditions for the Michael condensation, a number of efforts have been directed at the use of heterogeneous catalysts, which can be removed from the reaction mixture by filtration. Aluminium oxide, ${ }^{6}$ Zeolites, ${ }^{7} \mathrm{Mg}$-Al-Hydrotalcite, ${ }^{8} \mathrm{NiBr}_{2} / \mathrm{montmorillote}^{9}$ 
have use found in this domain and other catalysts with more or less success. ${ }^{10}$ We previously reported that natural phosphate, ${ }^{11}$ synthetic phosphate $\mathrm{Na}_{2} \mathrm{CaP}_{2} \mathrm{O}_{7},{ }^{12}$ fluoroapatite, ${ }^{13}$ and hydroxyapatite $^{14}$ are excellent catalysts of the Michael reaction.

In recent work, we have shown that doping with mineral salts increases the activity of solid catalysts. ${ }^{11}$ We have also shown that the catalytic is intimately related to the structure of the solid catalyst. ${ }^{15}$ Other researchers have augmented the effect of the catalyst with the addition of ultrasound $^{16}$ and microwave radiation. ${ }^{17}$

In continuation of our ongoing program to develop clean and economical processes for the production of fine chemicals, we present here, a practical and selective hydroxyapatite modified with sodium nitrate $(\mathrm{Na} / \mathrm{HAP})$ catalyzed Michael type addition of aliphatic and aromatic amines towards $\alpha, \beta$-unsatured carbonyl compounds (Scheme 1).

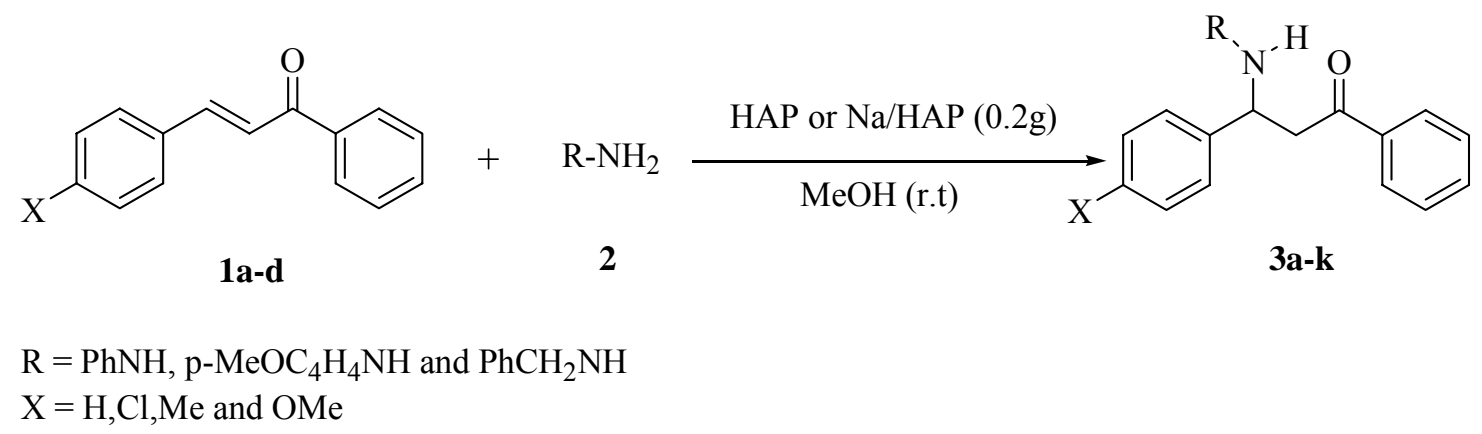

Scheme 1. Formation of carbon-nitrogen bond in the presence of HAP and Na/HAP catalysts.

\section{Results and Discussion}

The results for a variety of carbon-nitrogen bond formed by Michael condensation catalyzed by HAP and Na/HAP are summarized in Table 1. In general the use HAP alone as a heterogeneous catalyst in the Michael addition has allowed the isolation of the 1,4-addition product with low to modest yields (Table1). The yields seem to be limited even if the time of the reaction is prolonged. However, for all cases the reaction rate is very long. No by-products resulting from the undesirable 1,2-addition and/or bis-addition side reactions (usually observed under classical conditions in same cases) were observed. To improve the reactivity of the HAP, we used sodium nitrate supported on HAP (calcined at $900^{\circ} \mathrm{C}$ ) in different proportions. To determine the best weight report $\left(\mathrm{r}=\mathrm{NaNO}_{3} / \mathrm{HAP}\right.$ ), we have carried out the synthesis of product 3a at room temperature using the weight report of $\mathrm{r}=1 / 2,1 / 4,1 / 6,1 / 8,1 / 10$ and $1 / 12$. The best yield in product 3a is obtained with $r=1 / 2$ (Figure 1). It is worth noting that in the same conditions, no reaction occurred in presence of $\mathrm{NaNO}_{3} / \mathrm{HAP}$ calcined at 150,300 or $500{ }^{\circ} \mathrm{C}$. 


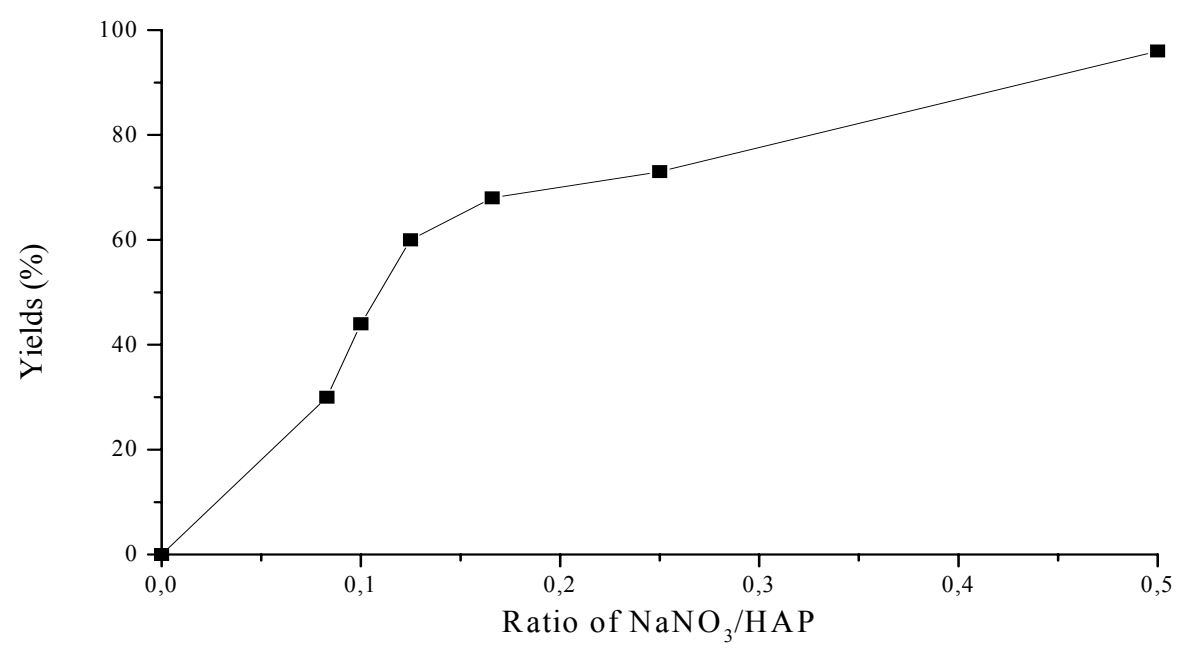

Figure 1. Yields of 3a using $\mathrm{NaNO}_{3} / \mathrm{HAP}$ with different weight ratio.

Firstly, we have tested the Na/HAP as basic catalyst in the construction of a carbon-nitrogen bond. Thus, various amount of $\mathrm{Na} / \mathrm{HAP}$ has been used to catalyse the condensation aniline and chalcone 1a (Figure 2). The results obtained indicate that Na/HAP is very active, in spite of the use of very small quantity $(0.1 \mathrm{~g})$. When we use amount $0.2 \mathrm{~g}$ of $\mathrm{Na} / \mathrm{HAP}$, the reaction is complete after $1.5 \mathrm{~h}$, the yield obtained is $96 \%$.

We have also proceeded to study the solvent effect in the synthesis 3a using the Na/HAP (0.2 g) catalyst. In the cases of hexane, acetone and dichlorometane, no product 3a was observed under the reaction conditions; only the starting material was isolated. A similar effect of solvent has been observed in the use of the natural phosphate alone or doped with potassium fluoride catalysts. ${ }^{11 \mathrm{a}}$ The use of $n$-butanol, iso-propanol, ethanol and methanol gave after $1.5 \mathrm{~h}$ of reaction 40, 33, 86 and 96\% yield of 3a, respectively. It can be concluded that methanol is the best solvent for this reaction. 


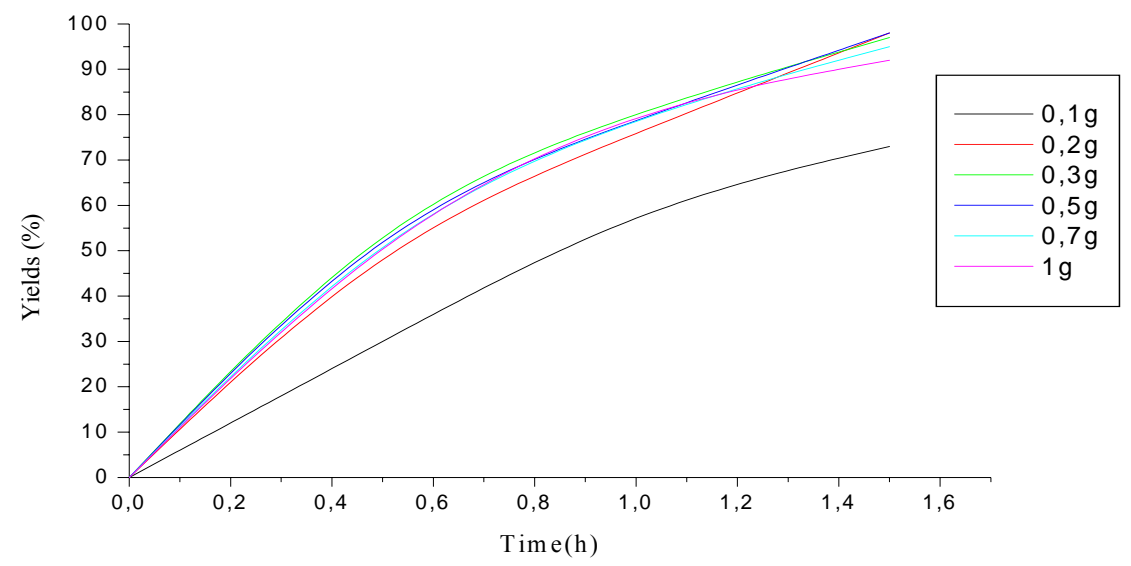

Figure 2. Influence of mass of $\mathrm{Na} / \mathrm{HAP}$ on conversion of aniline and chalcone.

Therefore, we carried out the construction of a carbon-nitrogen bond in various quantities of methanol (Figure 3). In absence of the solvent, no product 3a was observed; this behaviour indicates that some solvent is needed to facilitate the contact between the reagents and active site. On the other hand, in all cases, the methanol activated the reaction but the yields decrease when the quantity of methanol increases. This behaviour can be explained by the solvation of the reagents and the possibilities of contact between the active sites of catalyst and the organic substrates increase compared to the synthesis without a solvent. Beyond $2 \mathrm{~mL}$ of methanol, the dispersion phenomenon of the organic reagents can provoke a decrease of yields.

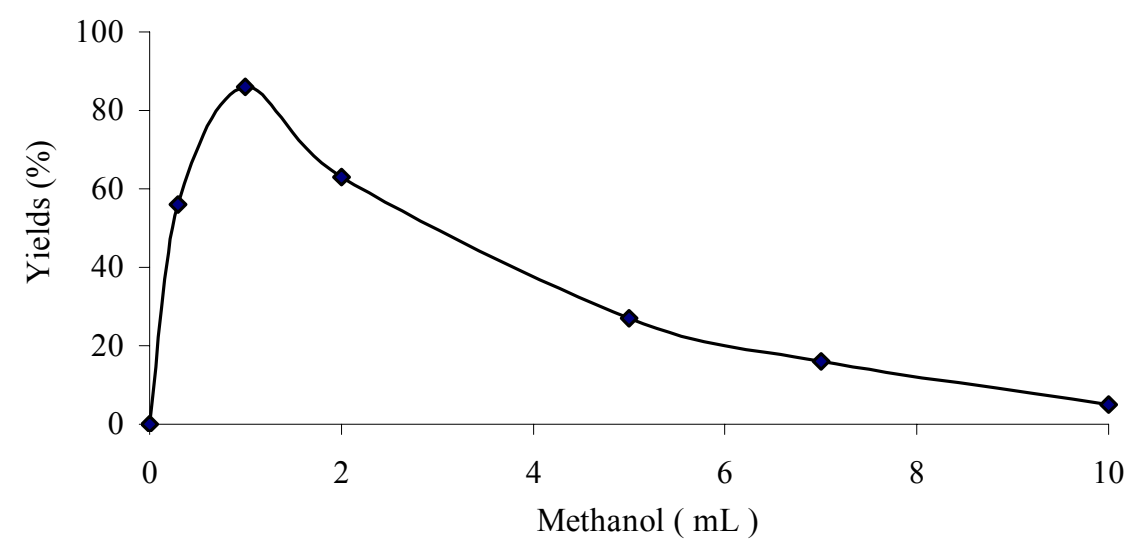

Figure 3. Volume effect in the construction of a carbon-nitrogen bond (3a). 
A solid catalyst is especially interesting when we can use it several times. This reuse gives the catalyst an advantage compared to other catalysts. Thus, the used and recovered NA/HAP has been shown to be reusable after drying at $150^{\circ} \mathrm{C}$ in vacuum, and more efficiently after washing with dichloromethane followed by calcination at $900{ }^{\circ} \mathrm{C}$ (Figure 4 ). In the last case, the catalyst can be recovered and least four times without appreciable loss of activity.

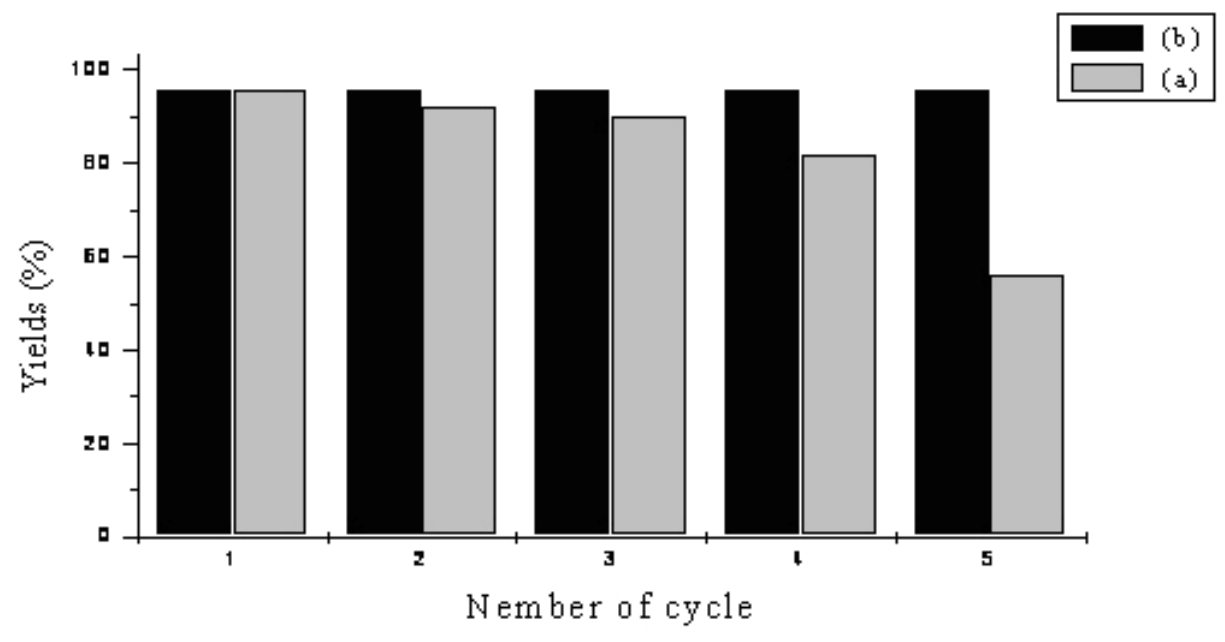

Figure 4. Recycling of the NA/HAP catalyst in the synthesis 3a: (a) catalyst recoverable dried at $150^{\circ} \mathrm{C}$ for $1 \mathrm{~h}$; (b) catalyst recoverable, washed with acetone, dried and calcined at $900{ }^{\circ} \mathrm{c}$ for 30 to $60 \mathrm{~min}$.

However, under the optimised conditions, the use of HAP modified by $\mathrm{NaNO}_{3}$, remarkably, increases the catalytic activity and decreases the reaction time of the construction of a carbonnitrogen bond (Figure 5).

In all cases the use NA/HAP as heterogeneous catalyst in the construction carbon-nitrogen bond with good to excellent yields (70-96\%. Table 1), except in the case where the nucleophile is benzylamine and Michael acceptor bearing a methoxy $(\mathrm{x}=\mathrm{MeO}$; Table 1$)$ in the para position. 


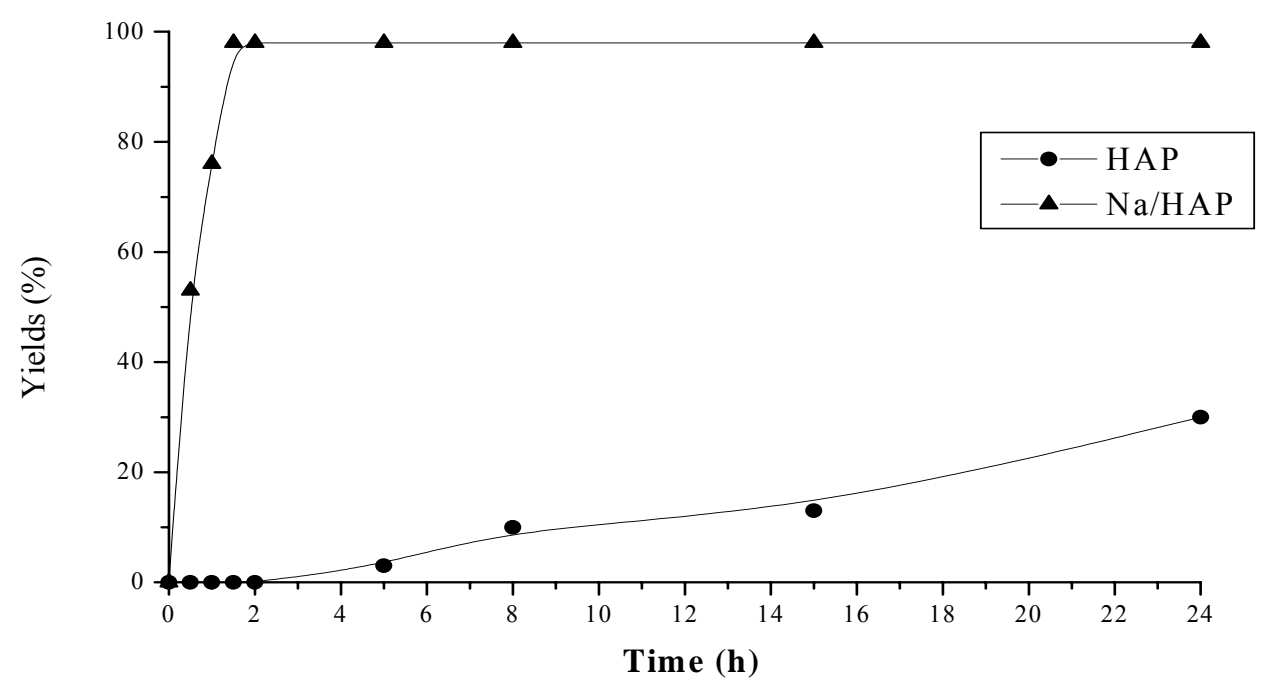

Figure 5. Time course of product $3 \mathbf{a}$ synthesis in the presence of HAP and Na/HAP, respectively.

For the catalytic activity of $\mathrm{Na} / \mathrm{HAH}$ in this Michael addition we speculate that the reaction occurs at the surface rather than inside tunnels of the catalyst. The surface of HAP to acidic character ${ }^{18}$ probably induced the polarization of the $\mathrm{C}=\mathrm{O}$ bond and the basic sites ${ }^{14}$ depronate $\mathrm{RH}_{2} \mathrm{~N}^{+}-\mathrm{C}$ after addition to the $\mathrm{C}=\mathrm{C}$ bond. The final product is obtained after protonation of the resulting enolate.

The $\beta$-amino carbonyl 3 is a direct precursor of $\beta$-amino acid. Scheme 2 illustrates our approach wherein the starting material is a 1,4 -adduct 3 . $\beta$-amino carbonyl $3 \mathbf{a}$ is converted to oxime $4 \mathbf{a}$, in the presence of our catalyst $\mathrm{Na} / \mathrm{HAP}$ in excellent yield (90\%). The oxime $4 \mathbf{a}$ was subjected to the reaction induced by thionyl chloride and the chemoselective Beckmann rearrangement gave the anilide of 3-phenyl-3-(N-phenylamino) propanoic acid 5a. Finally, after two steps, $\beta$-amino acid is obtained with a good yield (Scheme 2 ). 
Table 1. Construction of a carbon-nitrogen bond by Michael addition using HAP and Na/HAP as catalysts

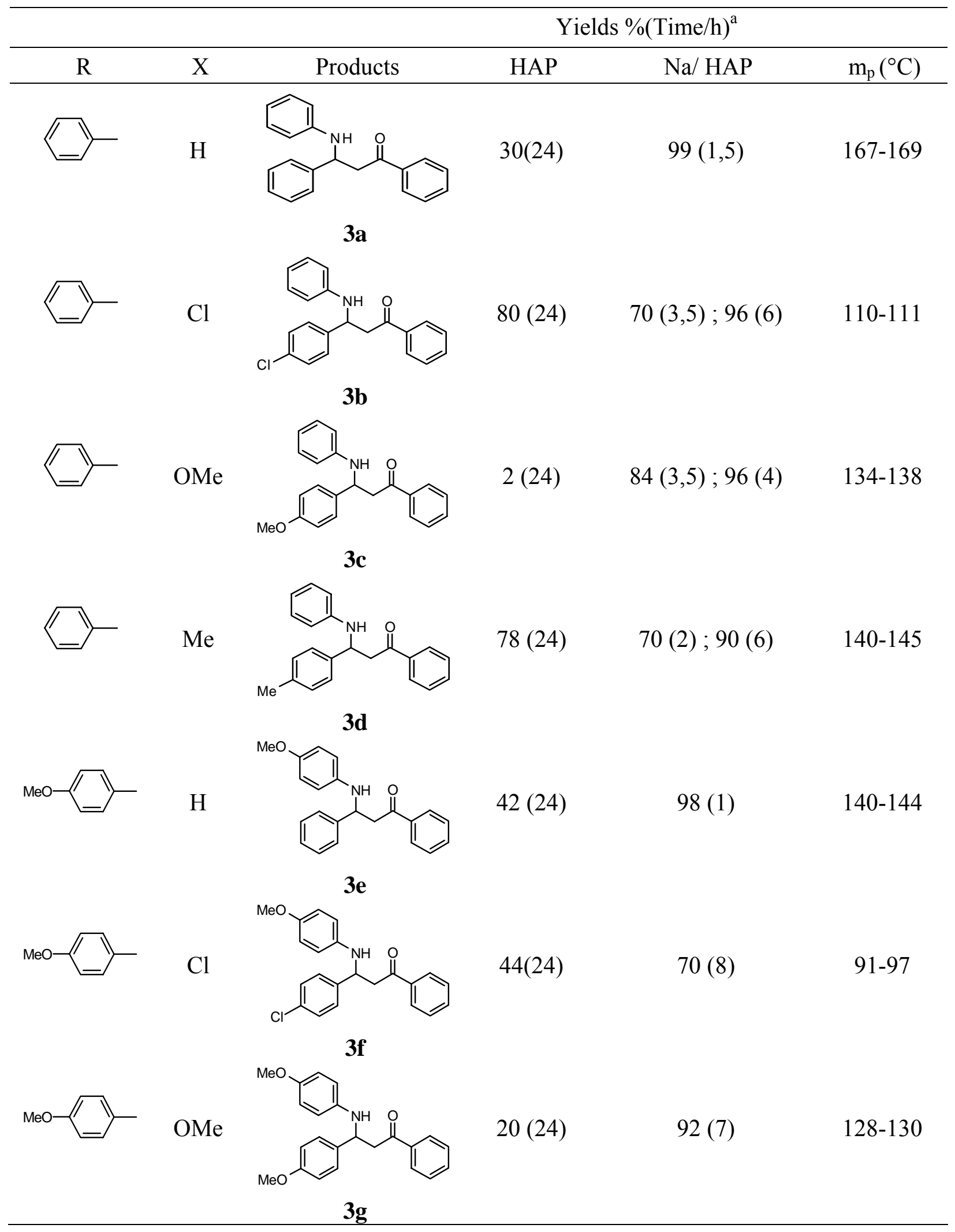


Table 1. Continued

$\longrightarrow \mathrm{CH}_{2} \quad \mathrm{H}$<smiles>O=C(CC(Nc1ccccc1)c1ccccc1)c1ccccc1</smiles>

$62(48)$

$94(5)$

$75-76$

$3 h$<smiles>[CH2-]c1ccccc1</smiles>

$\mathrm{Cl}$<smiles>O=C(CC(Nc1ccccc1)c1ccc(Cl)cc1)c1ccccc1</smiles>

$85(24)$

$83(5) ; 92(7)$

98-100 $\longrightarrow \mathrm{CH}_{2}^{-} \quad \mathrm{OMe}$<smiles>COc1ccc(C(CC(=O)c2ccccc2)Nc2ccccc2)cc1</smiles>

3j

$\longrightarrow \mathrm{CH}_{2} \quad \mathrm{Me}$<smiles>Cc1ccc(C(CC(=O)c2ccccc2)Nc2ccccc2)cc1</smiles>

$40(24)$

$70(24)$

56-61

$3 \mathbf{k}$

${ }^{a}$ Yields of pure products isolated by chromatography and recrystallized from $n$-hexane/ethyl acetate. The products were identified by ${ }^{1} \mathrm{H},{ }^{13} \mathrm{C}-\mathrm{NMR}$, IR spectroscopy and melting points.

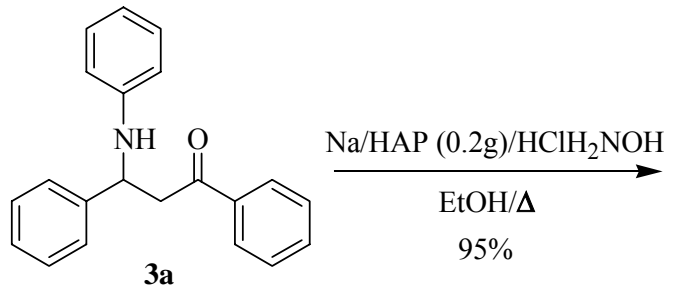<smiles>N=C(CC(Nc1ccccc1)c1ccccc1)c1ccccc1</smiles><smiles>O=C(CC(Nc1ccccc1)c1ccccc1)Nc1ccccc1</smiles><smiles>O=C(O)CC(Nc1ccccc1)c1ccccc1</smiles><smiles></smiles><smiles>CCOC(=O)CC(Nc1ccccc1)c1ccccc1</smiles>
$\mathrm{EtOH} / \mathrm{H}_{2} \mathrm{SO}_{4} / \Delta$

\section{Scheme 2}


In summary, we have reported that hydroxyapatite modified by sodium nitrate is an efficient catalyst for construction carbon-nitrogen bond of aliphatic and aromatic amines with $\alpha, \beta$ unsaturated carbonyl compounds at room temperature. The advantages of this method are an easy separation of the catalyst by filtration, under solvent-free conditions, possible recycling of the catalyst, elimination of salts and by-product pollutants, and applicability to aliphatic and aromatic amines at room temperature and the high yields obtained. Hydroxyapatite modified by sodium nitrate is used as the catalyst for the facile synthesis of $\beta$-amino acid under heterogeneous conditions. This solid base catalyst is certainly a practical alternative to existing methodologies for the construction carbon-nitrogen bond.

\section{Experimental Section}

\section{Preparation and characterization of HAP}

The synthesis of hydroxyapatite $(\mathrm{HAP})^{14}$ in powder state is carried out by means reaction between diammonium phosphate and calcium nitrate in presence of ammonia (Scheme 3).

HAP was obtained by co-precipitation method: $250 \mathrm{~mL}$ of a solution containing $7.93 \mathrm{~g}$ of diammonium hydrogen phosphate, maintained at a $\mathrm{pH}$ greater than 12 , by addition of ammonium hydroxide $(60-70 \mathrm{~mL})$, were dropped under constant stirring into $150 \mathrm{~mL}$ of a solution containing $23.6 \mathrm{~g}$ of calcium nitrate $\left[\mathrm{Ca}\left(\mathrm{NO}_{3}\right)_{2} 4 \mathrm{H}_{2} \mathrm{O}\right]$. The suspension was refluxed for $4 \mathrm{~h}$. Doubly distilled water (DDW) was used to prepare the solutions. The HAP crystallites were filtered, washed with DDW, dried overnight at $80^{\circ} \mathrm{C}$ and calcined in air at $900^{\circ} \mathrm{C}$ for $30 \mathrm{~min}$ before use.

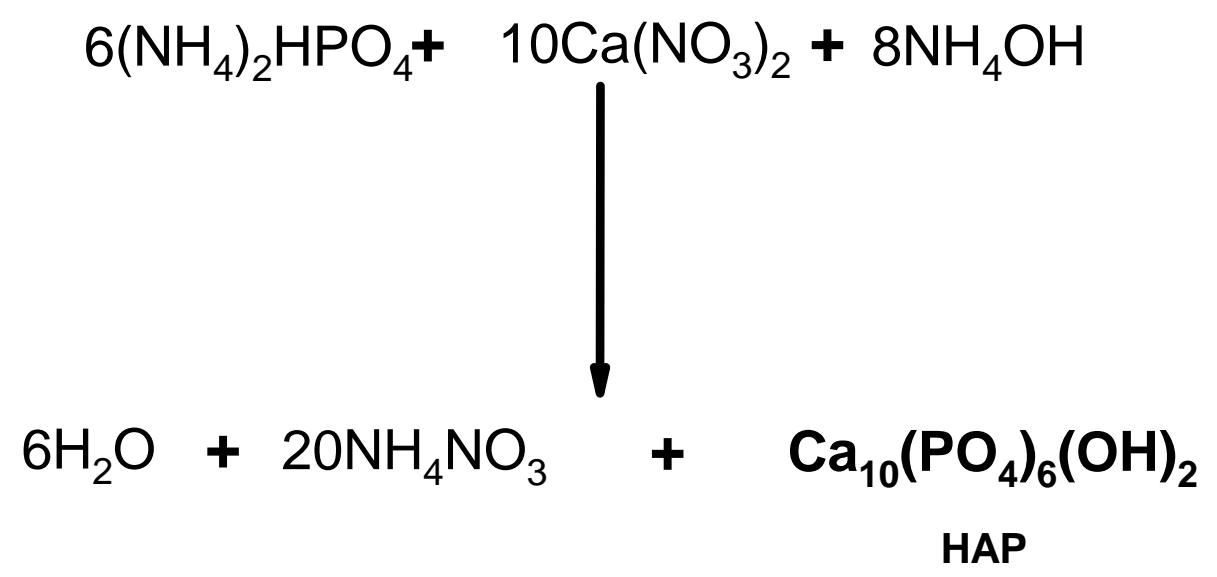

Scheme 3. Preparation of hydroxyapatite (HAP).

The final product is identified by X-ray diffraction (space group hexagonal system; $\mathrm{a}=9.422$ $\AA$ and $\mathrm{C}=6.883 \AA$ ), infrared spectra IR and chemical analysis. The surface area of calcined HAP was determined by BET method from adsorption-desorption isotherm of nitrogen at its 
liquid temperature $(77 \mathrm{k})$ and was found to be $\mathrm{S}=38.3 \mathrm{~m}^{2} / \mathrm{g}$. The total pore volume was calculated by $\mathrm{BJH}$ method at $\mathrm{P} / \mathrm{P} 0=0.98\left(\mathrm{VT}=0.157 \mathrm{~cm}^{3} / \mathrm{g}\right)$.

\section{Preparation and characterization of HAP modified by sodium nitrate Na/HAP}

HAP modified by sodium nitrate was prepared by adding a masse $\left(\mathrm{m}_{1}\right)$ of HAP to an aqueous solution of mass $\left(\mathrm{m}_{0}\right)$ of sodium nitrate. The mixture was stirred vigorously at room temperature, evaporated to dryness and dried at $100{ }^{\circ} \mathrm{C}$ for $2 \mathrm{~h}$. The $\mathrm{NaNO}_{3} / \mathrm{HAP}$ was calcined at $900^{\circ} \mathrm{C}$ for $1 \mathrm{~h}$ to give a new strong active catalyst.

The XRD patterns of $\mathrm{NaNO}_{3} / \mathrm{HAP}\left(\mathrm{m}_{0} / \mathrm{m}_{1}=1 / 2\right)$ calcined at $900{ }^{\circ} \mathrm{C}$ (noted $\mathrm{Na} / \mathrm{HAP}$ ) showed the apparition of new phases, one phase observed is probably $\mathrm{NaCaPO}_{4}$ obtained by exchange of sodium with calcium (Figure 6). No crystalline phase of $\mathrm{Na}_{2} \mathrm{O}$ was obtained. The surface area of the new catalyst $\mathrm{Na} / \mathrm{HAP}$ was determined by the BET method $\left(\mathrm{S}=1.55 \mathrm{~m}^{2} \mathrm{~g}^{-1}\right)$ and Langmuir method $\left(\mathrm{S}=1.84 \mathrm{~m}^{2} \mathrm{~g}^{-1}\right)$. The BJH desorption cumulative surface of pores between 17 and 3000 $\AA$ diameter was $0.44 \mathrm{~m}^{2} \mathrm{~g}^{-1}$. The single point total pore volume of pore inferior at $810 \AA$ diameter at $\mathrm{P} / \mathrm{P}_{0}=0.976$ was $0.00159 \mathrm{~cm}^{3} \mathrm{~g}^{-1}$ and the $\mathrm{BJH}$ desorption cumulative pore volume of pores between 17 and $3000 \AA$ diameter was $0.00419 \mathrm{~cm}^{2} \mathrm{~g}^{-1}$.

The TD/DTA analysis of not calcined $\mathrm{NaNO}_{3} / \mathrm{HAP}$ shown the endotherm at $290-306{ }^{\circ} \mathrm{C}$ without the lost of weight (melting of $\mathrm{NaNO}_{3}$ ) and the endotherm at $600-725^{\circ} \mathrm{C}$ with the lost of weight $(22.5 \%)$ (decomposition of $\left.\mathrm{NaNO}_{3}\right)$.

\section{General procedure for the construction of carbon-nitrogen bonds}

To a flask containing an equimolar mixture $(1.5 \mathrm{mmol})$ of nucleophile $2\left(\mathrm{Nu}=\mathrm{PhNH}_{2}, p\right.$ $\mathrm{MeOC}_{4} \mathrm{H}_{4}-\mathrm{NH}_{2}$ or $\mathrm{PhCH}_{2} \mathrm{NH}_{2}$ Scheme 1) and chalcone derivative 1 in methanol (1.5 mL), phosphate catalyst (Na/HAP) $0.2 \mathrm{~g}$ was added and the mixture was stirred at room temperature until completion of the reaction as monitored by thin layer chromatography (TLC). The reaction mixture was filtred and the catalyst washed with dichloromethane. After concentration of the filtrate under reduced pressure the residue was subjected to chromatography or recrystallization ( $n$-hexane/ethyl acetate) leading to the Michael adduct. The product structure was verified by ${ }^{1} \mathrm{H}$, ${ }^{13} \mathrm{C}$ NMR, IR spectrometry and melting points. 

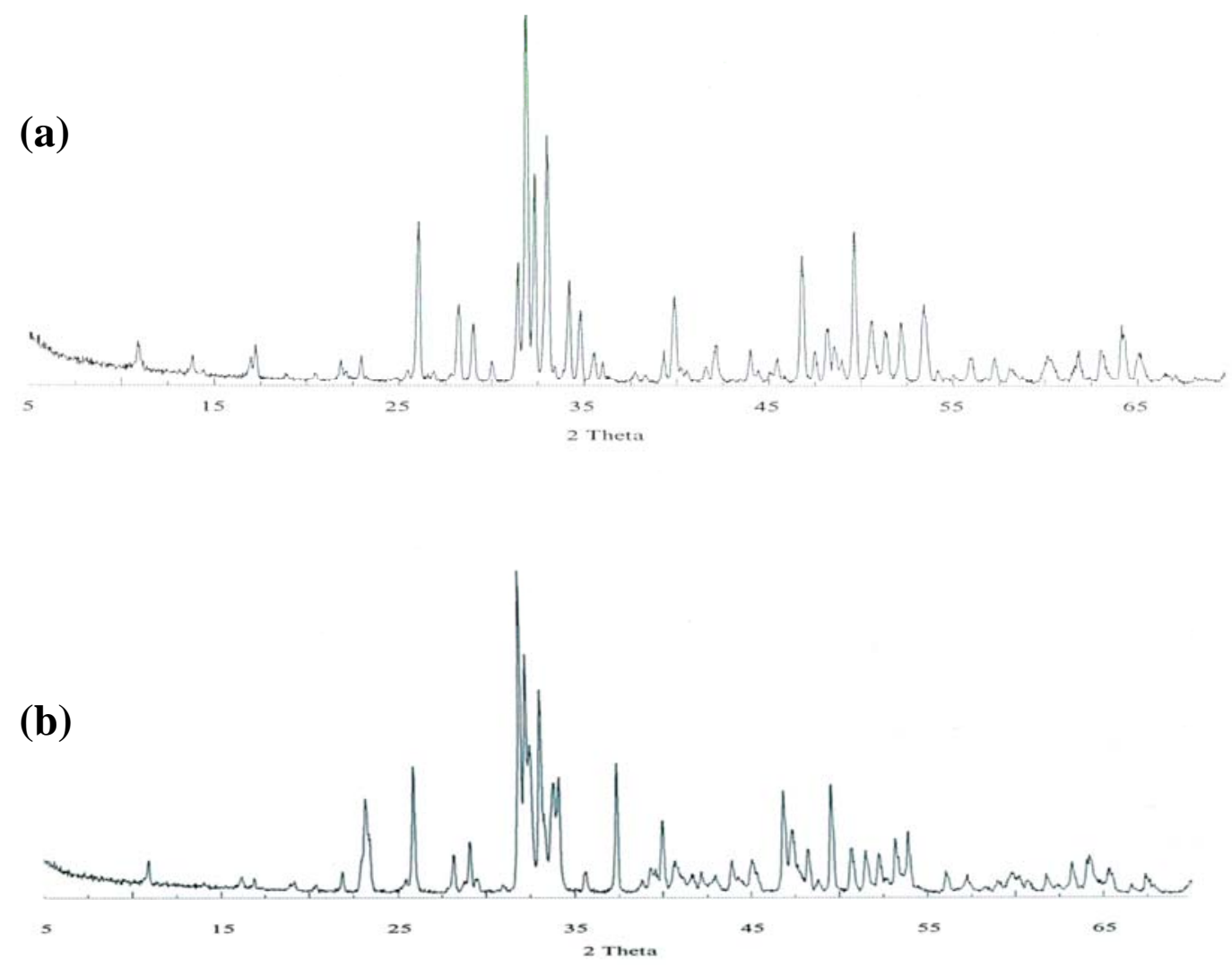

Figure 6. X-ray diffraction patterns of (a) HAP and (b) Na/HAP calcined at $900^{\circ} \mathrm{C}$.

\section{Recycling of the Na/HAP for the construction of carbon-nitrogen bond}

Using the same procedure as described above, the first run for construction of a carbon-nitrogen bond was carried out. After the reaction, the spent $\mathrm{Na} / \mathrm{HAP}$ was recovered by filtration; the isolated catalyst was dried at $150^{\circ} \mathrm{C}$ in vacuum before reuse. The yields obtained decreased progressively. For the other processing, the isolated Na/HAP was washed dichloromethane, dried at $100{ }^{\circ} \mathrm{C}$ and calcined at $900{ }^{\circ} \mathrm{C}$ before reuse. This recycling procedure was repeated four times in the same manner as for the first recycle.

\section{References}

1. (a) Sibi, M. P.; Deshpande, P. K. J. Chem. Soc., Perkin Trans. 1 2001, 1, 1461. (b) Cole, D. C. Tetrahedron 1994, 50, 9517. (c) Juaristi, E.; Quintana, D.; Escalante, J. Aldrichimica Acta 1994, 27, 3.

2. (a) Mayachi, N.; Shibasaki, M. J. Org. Chem. 1990, 55, 1975. (b) Tanner, D.; Somfai, P. Tetrahedron 1988, 44, 613. 
3. Nen Ayed, T.; Amiri, H.; El Gaied, M. M.; Villieras, J. Tetrahedron Lett. 1995, 35, 9633.

4. (a) Pfau, M. Bull. Soc. Chim. Fr. 1967, 117, (b) Perlmutter, P. Conjugate Addition Reactions in Organic Synthesis; Pergamon: Oxford, 1992.

5. (a) Furukawa, M.; Okawara, T.; Terawaki, Y. Chem. Pharm. Bull. 1977, 25, 1319. (b) D'Angelo, J.; Maddaluno, J. J. Am. Chem. Soc. 1986, 108, 8112. (c) Matsubara, S.; Yoshioka, M.; Utimoto, K. Chem. Lett. 1994, 827. (d) Jenner, G. Tetrahedron Lett. 1995, 36, 233.

6. (a) Ranu, B. C.; Bhar, S.; Sarkar, D.C. Tetrahedron Lett. 1991, 32, 2811. (b) Ranu, B. C.; Bhar, S. Tetrahedron 1992, 48, 1327. (c) Sharma, U.; Bora, U.; Boruah, R. C.; Sandhu, J. S. Tetrahedron Lett. 2002, 42, 143.

7. Sreekurnar, R.; Rugmimi, P.; Padmakumar, R. Tetrahedron Lett. 1997, 38, 6557.

8. Choudary, B. M.; Lakshmi Kantam, M.; Venkat Reddy, Ch.; Koteswara Rao, K.; Figueras, F. J. Mol. Catal. A: Chemical 1999, 146, 279.

9. Laszlo, P.; Montaufier, P. M-T.; Randriamahefa, S. L. Tetrahedron Lett. 1990, 31, 4867.

10. (a) Cheng, S.; Comer, D. D. Tetrahedron Lett. 2002, 43, 1179. (b) Kamimura, A.; Murakami, N.; Yokota, K.; Shirai, M.; Okamoto, H. Tetrahedron Lett. 2002, 43, 7521. (c) McDaid, P.; Chen, Y.; Deng, L. Angew. Chem. Int. Ed. 2002, 41, 338. (d) Bandini, M.; Cozzi, P. G.; Giacomini, M.; Melchiorre, P.; Selva, S.; Ronchi, A. U. J. Org. Chem. 2002, 67, 3700. (e) Wabnitz, T. C.; Yu, J.-Q.; Spencer, J. B. Synlett 2003, 1070. (e) Alam, M. M.; Varala, R. V.; Adapa, S. R. Tetrahedron Lett. 2003, 44, 5115. (f) Ranu, B. C.; Dey, S. S.; Hajra, A. Tetrahedron 2003, 59, 2417. (g) Ranu, B. C.; Dey, S. S. Tetrahedron 2004, 60, 4183.

11. (a) Abrouki, Y.; Zahouily, M.; Bahlaouan, B.; Rayadh, A.; Sebti, S. Tetrahedron Lett. 2002, 43, 8951. (b) Zahouily, M.; Bahlaouan, B.; Rayadh, A.; Sebti, S. Tetrahedron Lett. 2004, 45, 4135. (c) Zahouily, M.; Charki, H.; Abrouki, Y.; Mounir, B.; Bahlaouan, B.; Rayadh, A.; Sebti, S. Lett. Org. Chem. 2005, 2, 136.

12. Zahouily, M.; Abrouki, Y.; Rayadh, A. Tetrahedron Lett. 2002, 43, 7729.

13. Zahouily, M.; Abrouki, Y.; Rayadh, A.; Sebti, S.; Dhimane, H.; David, M. Tetrahedron Lett. 2003, 44, 2463.

14. Zahouily, M.; Abrouki, Y.; Bahlaouan, B.; Rayadh, A.; Sebti, S. Catal. Commun. 2003, 4, 521.

15. (a) Zahouily, M.; Bahlaouan, B.; Solhy, A.; Sebti, S. React. Kinet. Catal. Lett. 2003, 78, 129. (b) Bennazha, J.; Zahouily, M.; Boukhari, A.; Holt, E.-M. J. Mol. Catal. A: Chemical 2003, 202, 247.

16. (a) Li, J.-T.; Li, T.-S.; Cheng, X. Ultrason. Sonochem. 1999, 6, 199. (b) McNulty, J.; Streere, J. A.; Wolf, S. Tetrahedron Lett. 1998, 39, 8013. (c) Wang, S.-X.; Li, J.-T.; Wang, W.-Z.; Li, T.-S. Ultrason. Sonochem. 2002, 9, 159.

17. (a) Chang, S. K.; Chang, Y.-T. Synth. Commun. 1997, 27, 533. (b) Karchgaudhuri, N.; De, A.; Mitra, A. K. J. Chem. Res. 2002, 180.

18. Sebti, S.; Tahir, R.; Nazih, R.; Boulaajaj, S. Appl. Catal. A 2001, 218, 25. 